\title{
Penerapan Overhaul Engine Stand Kijang Menggunakan Alat-Alat Spesial Service Tool Di SMK NU 1 Adiwerna Kabupaten Tegal
}

\author{
Amin Nur Akhmadi ${ }^{*}$, M. Taufik Qurohman², Syaefani Arif Romadhon ${ }^{3}$ \\ ${ }^{1,2,3}$ Program Studi Teknik Mesin, Politeknik Harapan Bersama, Indonesia \\ Email: 19aminnurakhmadi@gmail.com, ${ }^{2}$ taufikqurohman87@gmail.com, ${ }^{3}$ syaefani1984@gmail.com
}

\section{INFORMASI ARTIKEL}

\section{Data artikel:}

Naskah masuk, 30 Juli 2019

Direvisi, 27 Agustus 2019

Diterima, 30 Agustus 2019

\section{Kata Kunci:}

Pelatihan

Overhaul engine

Alat-alat Service Toll

\begin{abstract}
ABSTRAK
Abstract- Vocational High School is the biggest contributor to unemployment in the area, many supporting factors such as the unstable condition of the company. Basically that is not all, the teaching process for these Vocational Schools is at the forefront of the increase in the unemployment rate of SMK graduates. From the results of community service activities, the following conclusions are obtained: (1) With the community service at Adiwerna District 1 Vocational High School, giving at Adiwerna $\mathrm{Nu} 1$ Vocational School in Tegal Regency, providing knowledge, understanding and innovation on efficient engine stand overhauls according to operational standards procedure; (2) Speeding up the work when the engine stand overhaul practices in competency subjects overhaul the engine with the SOP tool so as to make students competent in their performance practices.
\end{abstract}

\section{Korespondensi:}

\begin{abstract}
Abstrak - Sekolah Menengah Kejuruan adalah penyumbang terbesar angka pengangguran pada daerah tersebut, banyak beberapa faktor pendukung seperti halnya keadaan perusahaan yang tidak stabil. Pada dasarnya tidak itu saja, proses pengajaran pada SMK tersebut menjadi terdepan dalam peningkatan angka pengangguran tingkat lulusan SMK. Dari hasil kegiatan pengabdian kepada masyarakat diperoleh kesimpulan sebagai berikut : (1) Dengan adanya pengabdian masyarakat di SMK Nu 1 Adiwerna Kabupaten tegal maka memberikan di SMK Nu 1 Adiwerna kabupaten tegal maka memberikan pengetahuan, pemahaman dan inovasi terhadap overhaul engine stand yang efisien sesuai standar operasional prosedur; (2) Mempercepat pekerjaan pada saat praktek overhaul engine stand dalam mata pelajaran kompetensi overhaul mesin dengan alat yang SOP tersebut sehingga membuat siswa kompeten dalam praktek kinerjanya.
\end{abstract}

\section{Amin Nur Akhmadi}

Program Studi Teknik Mesin, Politeknik Harapan Bersama

Jl. Mataram No. 09, PesurunganLor, Kota Tegal, Indonesia 


\section{PENDAHULUAN}

Sekolah menengah kejuruan adalah penyumbang terbesar angka pengangguran pada daerah tersebut, banyak beberapa faktor pendukung seperti halnya keadaan perusahaan yang tidak stabil karena naik mahalnya biaya operasional akibat naik turun mata uang Dollar Amerika.

Selain itu juga angka pengangguran bagi lulusan sekolah menengah kejuruan adalah minimnya keterampilan yang dikuasai setelah tamat belajar. Pada dasarnya tidak itu saja, proses pengajaran pada SMK tersebut menjadi terdepan dalam peningkatan angka pengangguran tingkat lulusan SMK. Pada persaingan dunia pendidikan banyak bermunculan sekolah-sekolah baru dengan tingkat kesiapan yang minim, sehingga proses pembelajaran tidak bisa berjalan dengan maksimal tidak sesuai dengan prosedur yang tertuang pada pendirian sekolah tersebut (Somantri, Apriliani, Muhamad, \& Nishom, 2019).

Alat-alat yang memadai, ruang kelas dan praktikum yang representativ serta metode pembelajaran yang tepat adalah kunci utama meningkatkan kualitas lulusan dan ketrampilan lulusan yang diperoleh sehingga kemandirian masing-masing lulusan dapat dijadikan acuan untuk melamar pekerjaan (Akhmadi, Qurohman, \& Syarifudin, 2017). Penurunan kualitas dan level kompetensi akibat bisnis dunia pendidikan yang berkembang pesat sekarang ini.

Overhaul pada engine stand dewasa saat ini penting, dengan berbagai macam teknologi (Arraitz et al., 1999; Bangert \& Hawkins, 2003; Srinkanth et al., 2007) dan penerapannya $(\mathrm{Qu}, \mathrm{Liu}, \mathrm{Guo}, \mathrm{Zhu}, \&$ Tseng, 2018)sangat penting dan sangat terkait dengan pekerjaan di industri khususnya pada bidang otomotif. sehingga perlunya diadakan pengabdian masyarakat penerapan overhaul engine stand kijang menggunakan alat-alat spesial service tool Di SMK NU 1 Adiwerna Kabupaten Tegal Slawi.

sehingga kegiatan pelatihan ini dapat menambah keterampilan agar bisa digunakan pada saat mencari pekerjaan.

\section{METODE PELAKSANAAN}

Metode dalam kegiatan ini dilaksanakan dengan menggunakan metode ceramah dan praktek dengan alat peraga. Metode ini digunakan untuk menyampaikan materi pelatihan yang bersifat ringan dan menyenangkan untuk anak didik SMK Pelaksanaan metode ini digunakan waktu sebanyak $70 \%$ untuk praktek, sedangkan sisanya $30 \%$ digunakan untuk materi dan tanya jawab. Selain itu juga dilakukan pre-test dan post-test.

\section{HASIL DAN PEMBAHASAN}

Berdasarkan kegiatan pengabdian masyarakat yang telah dilaksanakan diperoleh hasil berdasarkan pengamatan langsung di SMK NU 1 Adiwerna Kabupaten Tegal telah dilaksanakan pelatihan overhaul engine stand mesin kijang dengan menggunakan alat-alat SST sesuai SOP kepada siswa di SMK tersebut, maka kegiatan pengabdian masyarakat ini menghasilkan hasil sebagai berikut:

a) Meningkatkan kualitas siswa SMK sehingga memiliki keahlian profesional dengan keterampilan dan keterampilan sesuai dengan tuntutan dengan kompetensi bidang otomotif.

b) Memperkenalkan kepada peserta didik terkait overhaul pada engine stand karena ini sangat terkait dengan pekerjaan di industri yang akan mereka hadapi dalam pekerjaan sehari - hari terkait dengan bidang otomotif, sehingga harapannya mereka dapat beradaptasi dengan lingkungan dengan lebih mudah.

c) Mempersiapkan generasi peserta didik yang lebih tanggap dengan era saat ini, apalagi diera revolusi industri 4.0 khususnya dibidang otomotif.

Pada Gambar 1 dan Gambar 2 memperlihatkan proses kegiatan pelatihan Kompetensi overhaul engine stand yang diikuti oleh para peserta kegiatan. Pada kegiatan ini proses kegiatan pembelajaran yang dilakukan oleh tim pelaksana PKM, dimana pada proses tersebut terdapat dosen dan peserta didik serta tim dari mahasiswa politeknik harapan bersama.

Dalam pelaksanaan kegiatan pelatihan Kompetensi overhaul tersebut untuk memperoleh hasil luaran yang optimal maka dilakukan pendampingan baik itu pada saat proses pelaksanaan maupun pasca pelaksanaan 
pelatihan praktek. Pada pelatihan ini Mahasiswa dilibatkan sebagai tim pendamping yang mendampingi peserta pelatihan agar setiap peserta dapat dengan mudah baik dalam proses overhaul engine kijang pada stand tersebut.

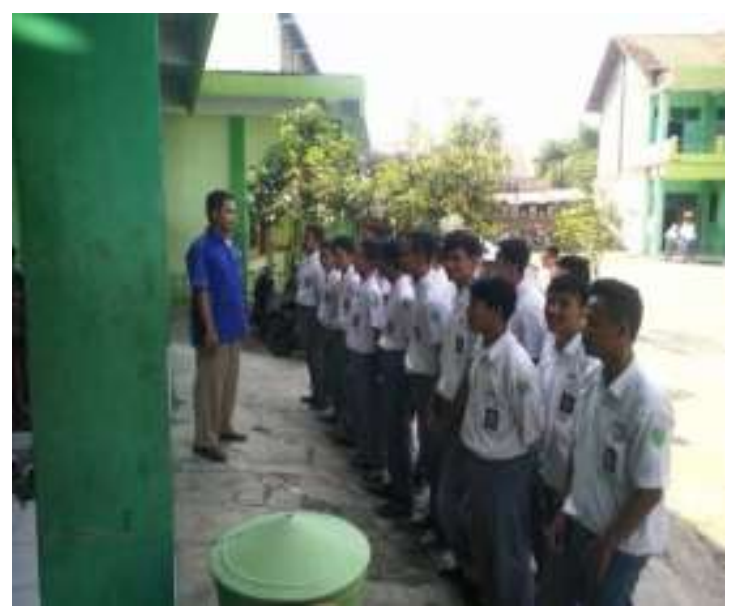

Gambar.1. Kegiatan Pengabdian di SMK NU Slawi

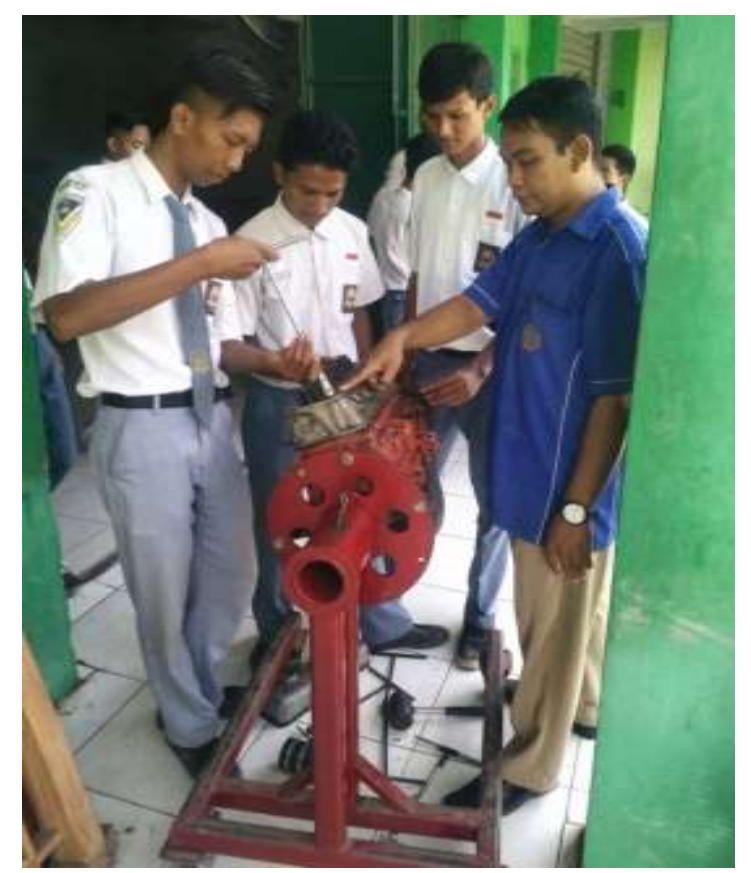

Gambar 2. Pemberian materi kepada peserta pelatihan

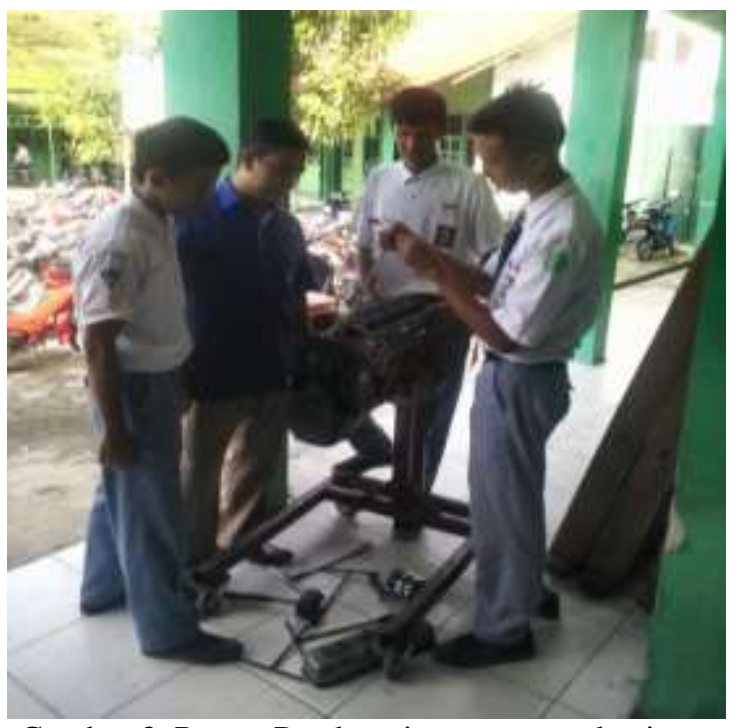

Gambar 3. Proses Pendampingan peserta kegiatan

Pada Gambar 3 memperlihatkan kegiatan pendampingan pada saat proses praktek, dimana pendampingan dilakukan oleh tim pelaksanaan PKM dan Mahasiswa. Pada proses pendampingan ini peserta kegiatan diarahkan dan dibimbing langsung face-to face sehingga harapannya dapat lebih optimal dalam proses

Kegiatan pengabdian pada masyarakat ini menghasilkan beberapa kegiatan yang dihasilkan diantaranya sebagai berikut: (1) Pemberian materi pelatihan yang diberikan kepada para siswa SMK NU 1 Slawi diterima dengan respon yang positif oleh para peserta kegiatan, disamping itu penggunaan media praktek engine stand yang dianggap untuk tambahan praktek engine stand oleh para peserta memberikan daya tarik tertentu bagi siswa sehingga banyak para peserta pelatihan yang tertarik; (2) Berdasarkan hasil praktek terhadap penggunaan engine stand kijang ini, telah dihasilkan beberapa konsep dalam overhaul dari Kompentensi mata pelajaran tentang mesinsehingga setelah kegiatan ini selesai para peserta kegiatan dapat langsung mempraktekannya; (3) Adanya ketertarikan dan keinginan dari kepala Sekolah SMK Nu 1 Slawi Kabupaten tegal untuk dapat mengimplementasikan hasil dari program pelatihan yang telah dilaksanakan. 


\section{KESIMPULAN}

Dari hasil kegiatan pengabdian kepada masyarakat Penerapan overhaul engine stand kijang menggunakan alat-alat special service toll dapat disimpulkan dengan adanya pengabdian masyarakat di SMK NU 1 Adiwerna Kabupaten tegal maka memberikan pengetahuan, pemahamam dan inivasi terhadap peralatan overhaul engine stand yang efisien sesuai standar Operasional Prosedur, selain itu mempercepat pekerjaan pada saat praktek overhaul engine stand dalam mata pelajaran kompetensi overhaul mesin dengan alat yang SOP tersebut sehingga membuat siswa kompeten dalam praktek kinerjanya

Untuk saran kedepannya seharusnya sering dilakukan pelatihan yang lebih intensif untuk lebih banyak memberikan kompetensi terbaru mengenai penggunaa peralatan bengkel yang sesuai standar operasional prosedur. Selain itu perlu adanya tindak lanjut dari Kepala Sekolah untuk memenuhi kebutuhan praktek jurusan yang sesuai dengan kompetensi otomotif standar operasional prosedur (SOP)

\section{DAFTAR PUSTAKA}

Akhmadi, A. N., Qurohman, M. T., \& Syarifudin, S. (2017). Peningkatan Kompetensi Auto CAD Bagi Siswa SMK Ma'arif NU Talang Kabupaten Tegal. Jurnal Abdimas PHB: Jurnal Pengabdian Masyarakat Progresif Humanis Brainstorming, 1(1). Retrieved from http://ejournal.poltektegal.ac.id/index.php /abdimas/article/view/683

Arraitz, A.-M., Bil, E. S., Hacault, M. G. P., Leray, L. P. Y., Loubet, M. J., Marchi, M. R., ... Thierry, C. S. (1999). Method of reducing the gap between a liner and a turbine distributor of a turbojet engine. Retrieved from https://patents.google.com/patent/US616 3959A/en

Bangert, B., \& Hawkins, R. (2003). Aircraft engine reliability business model. Retrieved from https://patents.google.com/patent/US664 3570B2/en

Qu, Y., Liu, Y., Guo, L., Zhu, Q., \& Tseng, M. (2018). Promoting remanufactured heavy-truck engine purchase in China: Influencing factors and their effects. Journal of Cleaner Production, 185, 8696.

https://doi.org/10.1016/J.JCLEPRO.2018. 02.188

Somantri, O., Apriliani, D., Muhamad, A. W., \& Nishom, M. (2019). Pembangunan Media Pembelajaran Berbasis E-Learning Di SMA NU Ma'Arif Jatinegara Tegal. CARADDE: Jurnal Pengabdian Kepada Masyarakat, 1(2), 189-194. https://doi.org/10.31960/caradde.v1i2.78

Srinkanth, A., Bourgeois, R. S., Aragones, J. K., Graham, M. E., Nirmalan, N. V., Adibhatla, S., \& Mazzaro, M. C. (2007). Method and system for planning repair of an engine. Retrieved from https://patents.google.com/patent/US200 90048730A1/en 